(c) American Dairy Science Association, 2003.

\title{
Antimicrobial Drug Susceptibility of Staphylococcus aureus Strains Isolated from Bovine and Ovine Mammary Glands
}

\author{
A. Pengov and S. Ceru \\ Institute for microbiology, Faculty of Veterinary Medicine, \\ 1000 Ljubljana, Gerbiceva 60, Slovenia
}

\begin{abstract}
The activity of selected antimicrobial agents against Staphylococcus aureus was determined with the agar disk diffusion test to determine the diameter of the zone of inhibition and the E-test for determination of the minimal inhibitory concentration (MIC). The $92 S$. aureus strains used in this study were isolated from bovine $(\mathrm{n}=76)$ and ovine $(\mathrm{n}=16)$ intramammary infections. Four antibiotics, which are frequently used in mastitis therapy were chosen: penicillin-G, ampicillin, kanamycin, and cephalexine. The fifth compound (oxacillin) was used to detect methicillin-resistant $S$. aureus, but no such strains could be found. According to the evaluation criteria, 65.2 (penicillin) to $93.5 \%$ (kanamycin, cephalexine) $S$. aureus strains were susceptible to the antibiotics tested. Ovine $S$. aureus strains reveal a lower resistance rate than bovine isolates. Comparison of the results of the two methods of susceptibility testing shows, with exception of penicillin and ampicillin, satisfactory agreement. Analyzing the results of the MIC endpoints and the zone diameter values, very major errors, according to the error rate bounded method of Metzler and DeHaan, occurred at an error rate of $3.3 \%$ for penicillin and 3.8\% for ampicillin. (Key words: antimicrobial drug susceptibility, Staphylococcus aureus, mastitis)
\end{abstract}

Abbreviation key: $\mathbf{M I C}=$ minimal inhibitory concentration, $\mathbf{N C C L S}=$ National Committee for Clinical Laboratory Standards.

\section{INTRODUCTION}

Staphylococcus aureus is a common cause of infection in the bovine (Lipman et al., 1996; Phuektes et al., 2001) and ovine (Beveridge, 1983; Pengov, 2001) mammary gland and also an important pathogen in humans (Easmon and Adlam, 1983). In the control of staphylococcal mastitis antibiotic therapy continues to play an important role (McDonald and Anderson, 1981; Craven et al., 1986). However, despite a variety of available antibiotics, success of treatment of $S$. aureus mastitis particularly during lactation is still very low (Matthews et al., 1994; Pengov et al., 2001). Clearly, there are several factors that influence the outcome of the therapy. Bacterial strains resistant to antimicrobial agents used in approved intramammary preparations might be one of the important reasons for therapy failure. Thus, information on susceptibility trends for a bacterial species within a given population is important $(\mathrm{Ow}-$ ens et al., 1997).

Antimicrobial susceptibility testing of the causal pathogens should permit the selection of the most appropriate therapeutic agent for therapy of mastitis (Wilson, 1973; Watts and Yancey, 1994). Basically, there are two methods to perform the susceptibility testing of pathogens. The agar diffusion method is technically easy to perform and, if strict quality control measures are applied, valuable information can be obtained. However, these tests have numerous shortcomings concerning their technical performance as well as the interpretation of the results. The minimum inhibitory concentration (MIC) determination is more accurate and provides an actual concentration indicating antibiotic potency against a particular bacterial species. For the veterinary clinical practice, recent susceptibility data for the common pathogens reported at the herd and regional level, as it is the case in this study, are of great value in the selection of specific antimicrobial agents.

The objective of the present study was to check the antibiotic resistance patterns of bovine and ovine mastitis isolates of $S$. aureus from several herds using the agar diffusion test for determination of the diameter of the zone of inhibition and the E-test for determination of the MIC.

\section{MATERIALS AND METHODS}

\section{Bacterial Strains}

Received September 23, 2002

Accepted January 3, 2003.

Corresponding author: A. Pengov; e-mail: Andrej.Pengov@vf. uni-lj.si.
Milk samples were collected from individual mammary quarters of cows $(\mathrm{n}=1282)$ and individual mam- 
mary halves of ewes $(n=436)$ in 18 dairy cow herds and two sheep flocks. Ninety-two isolates of $S$. aureus were selected for the antibiotic susceptibility testing. Sixteen strains were isolated from subclinical infected mammary halves of ewes, and 76 strains were isolated from subclinical infected mammary quarters of cows.

Milk samples were collected into autoclaved glass tubes following teat swabbing with $70 \%$ alcohol and after discarding the first streams of milk. Milk samples were kept cool and streaked with a sterile swab within $24 \mathrm{~h}$ on quarter plates of washed blood agar with $5 \%$ of sheep blood. Agar plates were then incubated at $37^{\circ} \mathrm{C}$. After $48 \mathrm{~h}$, plates were examined for aerobic bacterial growth. Gram-positive cocci were considered as Staphylococcus or Micrococcus species if they were catalase positive. Differences in hemolysin production were classified visually by an experienced observer as either $\beta$ hemolysin-positive (incomplete hemolysis with a sharply defined margin) or $\beta$-hemolysin negative (no hemolysis or another type of hemolysis) (Harmon et al., 1990; Jasper and Jain, 1966; Lam et al., 1995). The slide coagulase test was performed as described by the manufacturer (Biokar Diagnostics, France) of the rabbit-coagulase plasma. The slide-coagulase test, which detects bound coagulase, was considered positive if clumping was observed within $10 \mathrm{~s}$. If the reaction was weak, or if it occurred after $10 \mathrm{~s}$, the sample was judged as doubtful (Kloos and Smith, 1980).

For the final determination of $S$. aureus strains, we used the API-Staph test (Biomerieux, Macy I'Etolle France) (Kloos and Wolfshohl, 1982; Jasper et al., 1985).

\section{Agar Disk Diffusion Method}

With a sterile loop, the tops of four to five colonies of $S$. aureus from pure culture were picked up. The colonies were suspended in $5 \mathrm{ml}$ of sterile physiologic saline. The inoculum turbidity was standardized to equivalent of a 0.5 McFarland standard. The entire surface of a Mueller-Hinton agar plate was inoculated using a sterile swab. Disks containing $10 \mu \mathrm{g}$ of penicillin, $10 \mu \mathrm{g}$ of ampicillin, $30 \mu \mathrm{g}$ of cephalexine, $1 \mu \mathrm{g}$ of oxacillin, and $30 \mu \mathrm{g}$ of kanamycin were placed using a sterile forceps onto the agar surface and gently pressed down to ensure contact. Plates were incubated at $35^{\circ} \mathrm{C}$ for $20 \mathrm{~h}$. Subsequently, the diameter of the zone of inhibition around each disk was measured. This procedure is conforming to the National Committee for Clinical Laboratory Standards (NCCLS) documents M31-A2 and M2-A7.

\section{E-Test Method}

The E-test was performed according to the manufacturer's (AB Biodisk, Solna, Sweden) instructions.
Mueller-Hinton agar $(20 \mathrm{ml})$ was dispensed in $90-\mathrm{mm}$ diameter petri dishes. To determine MIC methicillinresistant $S$. aureus strains, we used Mueller-Hinton agar supplemented with $2 \% \mathrm{NaCl}$. The preparation of the inoculum was the same as for the disk diffusion test. A sterile swab was dipped into the inoculum and excess fluid was removed by rotating the swab against the glass wall of the tube. The agar plate was then inoculated by swabbing the entire surface three times in different directions to obtain a confluent growth. After drying at room temperature for 15 min E-test strips were placed centrally on each of the three plates per isolate. The plates were incubated for up to $18 \mathrm{~h}$ at $35^{\circ} \mathrm{C}$. Plates with $\mathrm{MHA}+2 \% \mathrm{NaCl}$ were incubated for up to $48 \mathrm{~h}$ at $35^{\circ} \mathrm{C}$. After incubation, the plates were examined for the formation of an elliptical zone of inhibited growth. The MIC was read from the scale on the strip, where the elliptical zone of growth inhibition intersected the strip.

Zone diameter interpretive standards and MIC breakpoints for veterinary pathogens are listed in Table 1.

One problem in susceptibility testing of bacteria is the relationship of the MIC of a strain, as determined by a dilution technique, to the size of the zone of inhibition of that strain, as determined by a disk diffusion technique. In the NCCLS document M23-A2 an "error rate-bounded" classification scheme is proposed for relating MIC and zone size of bacteria. The Metzler and DeHaan (1974) method usually needs to be modified because two MIC breakpoints are normally described to define an "intermediate" category. The original error rate-bounded method was modified by Brunden et al. (1992). Data should be displayed as a scattergram with zone diameters on the $\mathrm{x}$-axis and MIC on the y-axis, and with horizontal and vertical lines showing the proposed interpretive breakpoints.

With this method the relative importance of three types of discrepancies between the tests can be determined:

- false-susceptible disk diffusion test results-very major errors;

- false-resistant disk diffusion test results-major errors;

- cases when one of the test results is intermediate and the other is susceptible or resistant-minor errors.

When a large proportion of strains is close to the proposed or approved breakpoint for an antimicrobial agent, a high percentage of minor discrepancies may be expected. Because of the inherent +1 dilution variation in MIC endpoints, discrepancy rates will be directly 
Table 1. Detection of Susceptibility (in accordance to National Committee for Clinical Laboratory Standards document M31-A2).

\begin{tabular}{|c|c|c|c|c|c|c|}
\hline \multirow[b]{2}{*}{ Antibiotic } & \multicolumn{3}{|c|}{$\mathrm{ADD}^{1}(\mathrm{~mm})$} & \multicolumn{3}{|c|}{$\operatorname{MIC}^{2}(\mu \mathrm{g} / \mathrm{ml})$} \\
\hline & $S^{3}$ & I & $\mathrm{R}$ & $\mathrm{S}$ & I & $\mathrm{R}$ \\
\hline Penicillin-G (10IE) & $\geq 29$ & . & $\leq 28$ & $\leq 0.12$ & 0.19 & $\geq 0.25$ \\
\hline Ampicillin $(10 \mu \mathrm{g})$ & $\geq 29$ & & $\leq 28$ & $\leq 0.25$ & & $\geq 0.5$ \\
\hline Cephalexine $(30 \mu \mathrm{g})$ & $\geq 18$ & $15-17$ & $\leq 14$ & $\leq 8$ & 16 & $\geq 32$ \\
\hline Oxacillin $(1 \mu \mathrm{g})$ & $\geq 13$ & $11-12$ & $\leq 10$ & $\leq 2$ & & $\geq 4$ \\
\hline Kanamycin $(30 \mu \mathrm{g})$ & $\geq 18$ & $14-17$ & $\leq 13$ & $\leq 16$ & 32 & $\geq 64$ \\
\hline
\end{tabular}

${ }^{1} \mathrm{ADD}=$ Agar disk diffusion test.

${ }^{2} \mathrm{MIC}=$ Minimal inhibitory concentration.

${ }^{3} \mathrm{~S}=$ Sensitive, $\mathrm{I}=$ intermediate, $\mathrm{R}$ = resistant.

proportional to the percentage of isolates with antibiotic MIC in the range of one twofold concentration above the intermediate MIC $(\mathrm{I}+1)$ and one twofold concentration below the intermediate MIC (I - 1). Thus, when an entire population is used as the denominator for calculating discrepancy rates, the rate will be determined largely by the population of MIC in the I +1 to $\mathrm{I}-1$ range. For example, when $90 \%$ of the isolates have highly susceptible drug MIC (as is common with newer antibiotics), the discrepancy rate will be considerably less than that of a population in which $40 \%$ of the MIC fall in the $I+1$ to $I-1$ range. If the total $I+1$ to $I-$ 1 subpopulation is used as the denominator for calculating the discrepancies in this range, the discrepancy rates should be more comparable.

Of greater concern are discrepancies that occur with MIC twofold or greater concentrations above $(>\mathrm{I}+2)$ or below $(<\mathrm{I}-2)$ the intermediate MIC. These should be uncommon, and when they do occur, both the MIC and disk diffusion test should be repeated values used in the scattergram. Based on the data from the scattergrams of drugs for which interpretive criteria have been approved by NCCLS, the values listed in Table 2 are provided as a guideline for acceptable discrepancy rates using specific MIC subpopulations as the denominator. When there is a two-dilution intermediate range, the process for determining discrepancy rates remains the same with one modification. The MIC range of $\mathrm{I}+$
1 to I - 1 will include both intermediate MIC plus one dilution above the higher intermediate MIC and one dilution below the lower intermediate MIC. As an example, if the intermediate range is 2 and $4 \mu \mathrm{g} / \mathrm{ml}$, the MIC range of I +1 to I -1 will include $8,4,2$, and $1 \mu \mathrm{g} / \mathrm{ml}$ (see also Table 2). When there is no intermediate range, i.e., when there is only a susceptible and resistant breakpoint, the process for determining discrepancy rates is done in a similar manner (see Table 3). If there are no intermediate ranges for both disk diffusion and dilution testing, minor discrepancies are not a consideration (NCCLS document M23-A2).

\section{RESULTS AND DISCUSSION}

In the present study, four compounds (penicillin, ampicillin, kanamycin, and cephalexine), which are frequently used in mastitis therapy, were tested for their antimicrobial activity against bovine and ovine strains of $S$. aureus. The fifth compound (oxacillin) was used to reveal methicillin-resistant $S$. aureus strains demonstrate a methicillin MIC of $\geq 16 \mu \mathrm{g} / \mathrm{ml}$ and an oxacillin or nafcillin MIC of $\geq 8 \mu \mathrm{g} / \mathrm{ml}$ (Thorsberry and McDougal, 1983). As is shown in Figure 3, all of the 92 tested $S$. aureus strains were under this breakpoint. All strains of $S$. aureus ( $\mathrm{n}=92,100 \%)$ were in both tests classified as susceptible for oxacillin. No errors between the tests were observed (see Figure 1). In general, the suscepti-

Table 2. Guideline acceptable discrepancy rates (with intermediate ranges) (in accordance with National Committee for Clinical Laboratory Standards document M 23-A2) ${ }^{1}$.

\begin{tabular}{llllr}
\hline & & \multicolumn{3}{c}{ Discrepancy rates } \\
\cline { 3 - 4 } $\begin{array}{l}\text { 1-Dilution } \\
\text { intermediate range }\end{array}$ & $\begin{array}{l}\text { 2-Dilution } \\
\text { intermediate range }\end{array}$ & $\begin{array}{l}\text { Very } \\
\text { major }\end{array}$ & Major & Minor \\
\hline$\geq 1+2$ & $\geq \mathrm{I}_{\text {high }}+2$ & $<2 \%$ & NA & $<5 \%$ \\
$\mathrm{I}+1$ to $\mathrm{I}-1$ & $\mathrm{I}_{\text {high }}+1$ to $\mathrm{I}_{\text {low }}-1$ & $<10 \%$ & $<10 \%$ & $<40 \%$ \\
$\leq 1-2$ & $\leq \mathrm{I}_{\text {low }}-2$ & NA & $<40 \%$ & $<5 \%$ \\
\hline${ }^{1} \mathrm{I}_{\text {high }}$ and $\mathrm{I}_{\text {low }}$ are the higher and lower minimum inhibitory & concentration in a two-dilution intermediate \\
range.
\end{tabular}


Table 3. Guideline acceptable discrepancy rates (no intermediate ranges) (in accordance to National Committee for Clinical Laboratory Standards document M $23-$ A2). ${ }^{1}$

\begin{tabular}{lccr}
\hline MIC Range & \multicolumn{3}{c}{ Discrepancy rates } \\
\cline { 2 - 4 } $\begin{array}{l}\text { No } \\
\text { intermediate } \\
\text { range }\end{array}$ & $\begin{array}{l}\text { Very } \\
\text { major }\end{array}$ & Major & Minor \\
\hline$\geq \mathrm{R}+1$ & $<2 \%$ & $\mathrm{NA}$ & $<5 \%$ \\
$\mathrm{R}+\mathrm{S}$ & $<10 \%$ & $<10 \%$ & $<40 \%$ \\
$\leq \mathrm{S}-1$ & $\mathrm{NA}$ & $<2 \%$ & $<5 \%$ \\
\hline
\end{tabular}

${ }^{1} \mathrm{R}$ is the resistant breakpoint minimal inhibitory concentration (MIC); $\mathrm{S}$ is the susceptible breakpoint MIC.

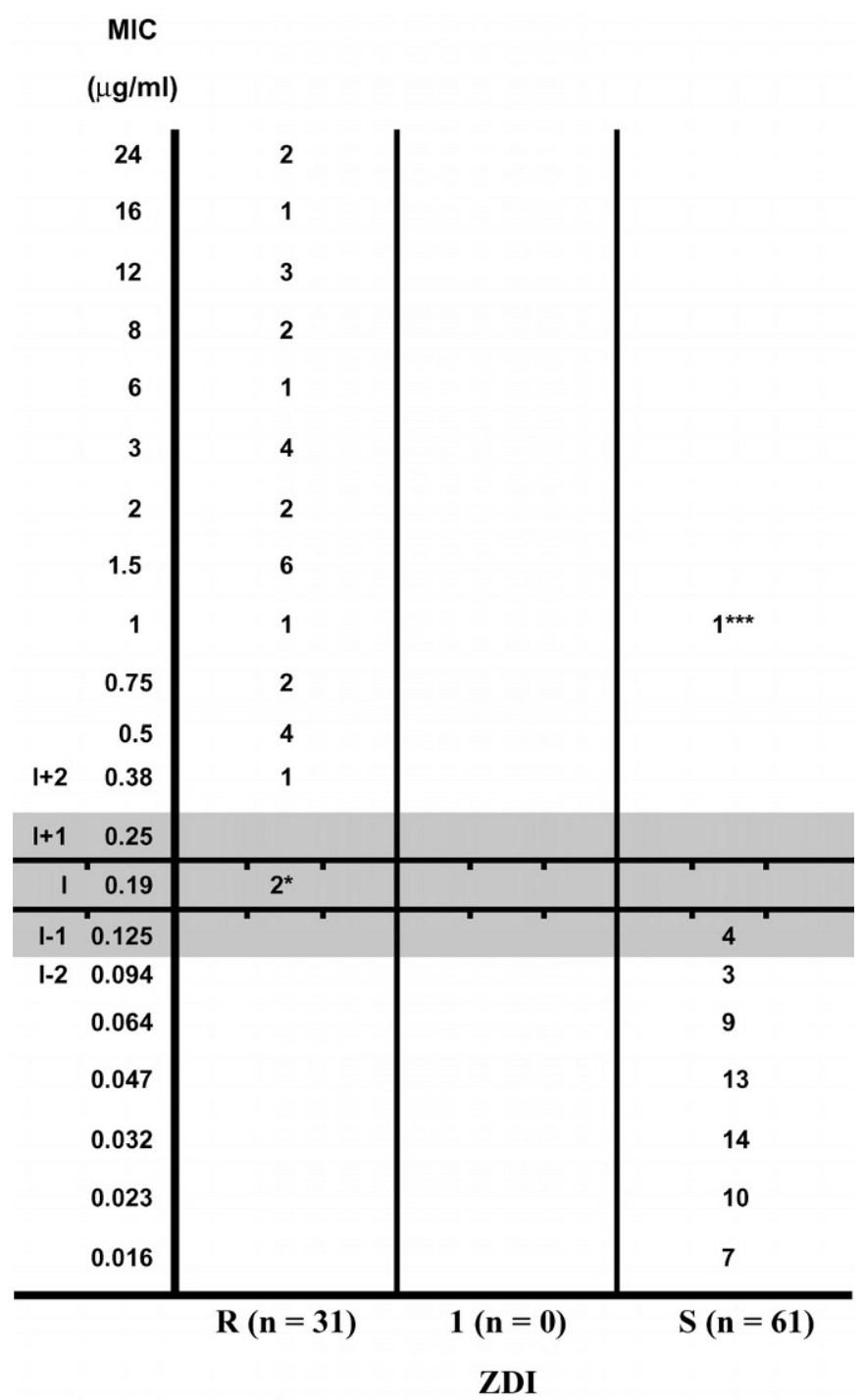

Figure 1. Comparison of the diameter of the zone of inhibition and the minimal inhibitory concentration of 92 Staphylococcus aureus strains for ampicillin. Distribution of the strains between interpretation zones $\mathrm{S}$ and $\mathrm{R}$ for the disk diffusion and the E-test (MIC). ZDI $=$ Zone diameter interpretation $; \mathrm{MIC}=$ minimal inhibitory concentration; $\mathrm{S}=$ sensitive $\geq 29 \mathrm{~mm} ; \mathrm{S}=$ sensitive $\leq 0.25(\mu \mathrm{g} / \mathrm{ml}) ; \mathrm{R}=$ resistant $\leq 28 \mathrm{~mm} ; \mathrm{R}=$ resistant $\geq 0.5(\mu \mathrm{g} / \mathrm{ml}) ; * * *$ very major error. bility rate of $S$. aureus strains for the antibiotics that were used in this study was surprisingly high.

The described error rate-bounded method modified by Brunden et al. (1992) was used to express the differences between the results of the agar disk diffusion method and the E-test.

Sixty strains $(65.2 \%)$ of $S$. aureus were classified as susceptible for penicillin $\mathrm{G}$ according to the zone of inhibition diameters $(\geq 29 \mathrm{~mm})$ and the minimal inhibitory concentration values $\geq 0.12(\mu \mathrm{g} / \mathrm{ml}), 29$ strains $(31.5 \%)$ were in both tests classified as resistant. In two cases $(2.2 \%)$ a minor error was detected between the tests. Both strains were classified according to the zone of inhibition as resistant and intermediate according to the MIC value. A very major error occurred in only one case (1.1\%). This strain was classified as sensitive according to the zone of inhibition diameter and as resistant according to the MIC value (see Figure 2 and Table 4).

Sixty-two strains (67.4\%) of S. aureus were classified as susceptible for ampicillin according to the zone of inhibition diameters $(\geq 29 \mathrm{~mm})$ and the MIC values $\leq 0.25(\mu \mathrm{g} / \mathrm{ml}) ; 29$ strains $(31.5 \%)$ were in both tests classified as resistant. A very major error between the tests was detected in only one case (1.1\%). This strain was classified as sensitive according to the zone of inhibition and resistant according to the minimal inhibitory concentration value (see Figure 3 and Table 5).

Eighty-six strains (93.5\%) of S. aureus were classified as susceptible for kanamycin according to the zone of inhibition diameters $(\geq 18 \mathrm{~mm})$ and the MIC values $\leq 0.16(\mu \mathrm{g} / \mathrm{ml})$. In six cases $(6.5 \%)$, a minor error was detected between the tests. These strains were according to the zone of inhibition diameter classified as sensitive and according to the MIC value as intermediate (see Figure 4).

Eighty-six strains (93.5\%) of S. aureus were classified as susceptible for cephalexine according to the zone of inhibition diameters $(\geq 18 \mathrm{~mm})$ and the minimal inhibitory concentration values $\leq 8(\mu \mathrm{g} / \mathrm{ml})$. Two strains $(2.2 \%)$ were in both tests classified as intermediate. In four cases $(4.3 \%)$, a minor error was detected between the tests. Two strains were according to the zone of inhibition diameter classified as sensitive and according to the minimal inhibitory concentration value as intermediate. In two cases, the strains were according to the zone of inhibition diameter classified as intermediate and according to the MIC value as sensitive (see Figure 5).

The results of two different test methods that were applied (agar diffusion and E-test) were, with the exception of penicillin and ampicillin, in satisfactory agreement (below the acceptable discrepancy rates; Tables 2 and 3). Analyzing the results of the MIC end- 


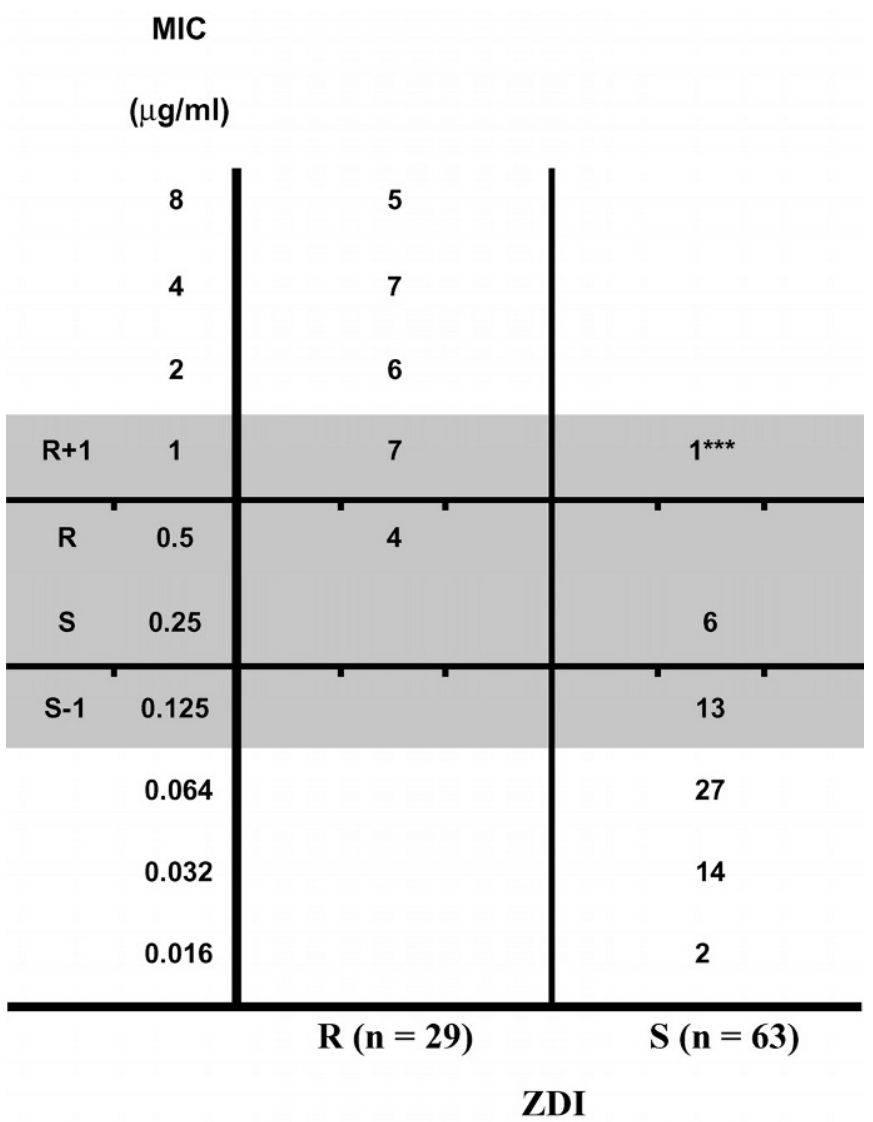

Figure 2. Comparison of the diameter of the zone of inhibition and the minimal inhibitory concentration of 92 Staphylococcus aureus strains for penicillin G. Distribution of the strains between interpretation zones S, I, and R for the disk diffusion and the E-test (MIC). $\mathrm{ZDI}=$ Zone diameter interpretation; $\mathrm{MIC}=$ minimal inhibitory concentration; $\mathrm{S}=$ sensitive $\geq 29 \mathrm{~mm} ; \mathrm{I}-1=(\mathrm{S}-$ sensitive $) ; \leq 0.12(\mu \mathrm{g} /$ $\mathrm{ml}) ; \mathrm{I}=$ intermediate -; I = intermediate $0.19(\mu \mathrm{g} / \mathrm{ml}) ; \mathrm{R}=$ resistant $\leq 28 \mathrm{~mm} ; \mathrm{I}+1=(\mathrm{R}=$ resistant $) ; \geq 0.25(\mu \mathrm{g} / \mathrm{ml}) ; *$ = minor error; $* * *$ $=$ very major error.

points and the zone diameter values, very major errors occurred at an error rate of 3.3\% for penicillin and 3.8\% for ampicillin. Ideally, when evaluating a large collection of unselected isolates, very major discrepancy rates should be less than $1.5 \%$. However, because only 92 strains were tested in this study and only 30 (penicillin) MIC (Table 4) fell in the $\geq \mathrm{I}+2$ range (and at least 50 would be required for one discrepancy to equal $2 \%$ ), this should be considered acceptable, particularly since

Table 4. Discrepancy rates for penicillin G.

\begin{tabular}{llllc}
\hline MIC Range & Number & Very Major & Major & Minor \\
\hline$\geq 1+2$ & 30 & $1(3.3)$ & NA & 0 \\
I +1 to I -1 & 6 & 0 & 0 & $2(33.3)$ \\
$\leq$ I -2 & 56 & NA & 0 & 0 \\
Total & 92 & $1(1.1)$ & 0 & $2(2.2)$ \\
\hline
\end{tabular}

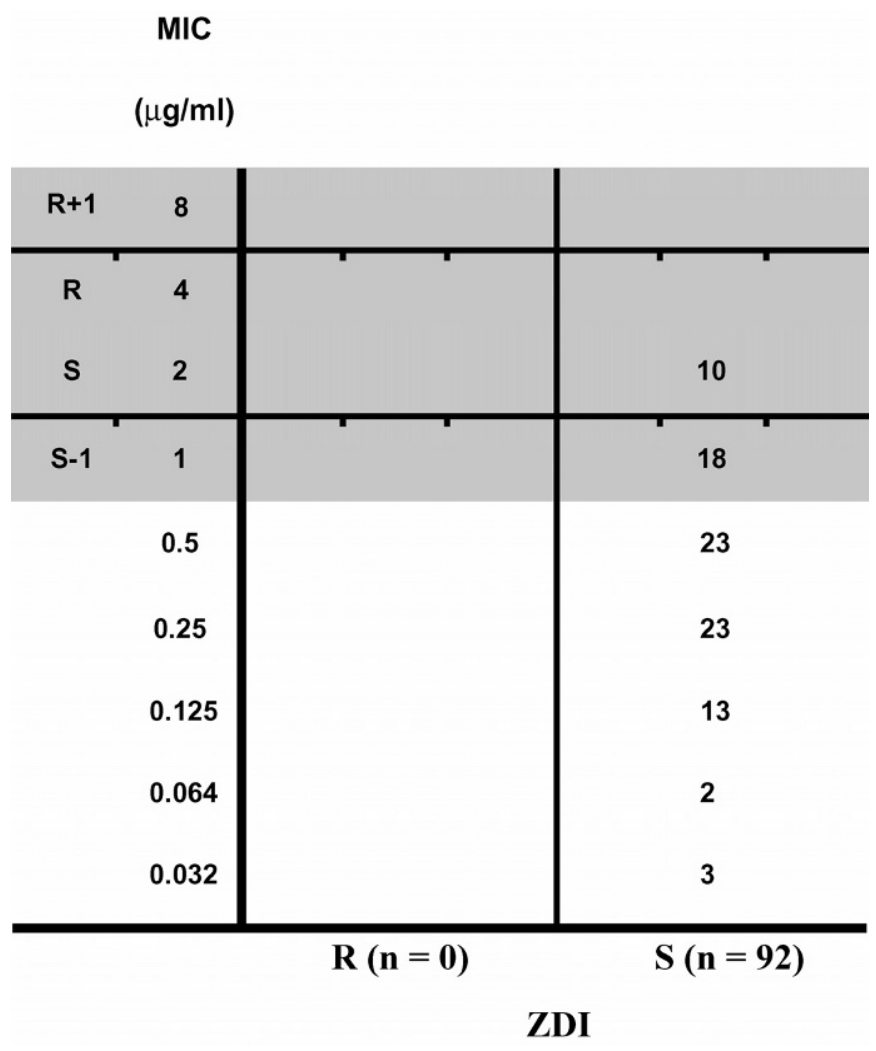

Figure 3. Comparison of the diameter of the zone of inhibition and the minimal inhibitory concentration of 92 Staphylococcus aureus strains for oxacillin. Distribution of the strains in the interpretation zone $\mathrm{S}$ and $\mathrm{R}$ for the disk diffusion and the E-test (MIC). ZDI = Zone diameter interpretation; MIC = minimal inhibitory concentration; $\mathrm{S}$ $=$ sensitive $\geq 13 \mathrm{~mm} ; \mathrm{S}=$ sensitive $\leq 2(\mu \mathrm{g} / \mathrm{ml}) ; \mathrm{R}=$ resistant $\leq 10$ $\mathrm{mm} ; \mathrm{R}=$ resistant $\geq 4(\mu \mathrm{g} / \mathrm{ml})$.

the overall discrepancy rates are significantly lower. In case of ampicillin (Table 5), 26 MIC were in the $\geq R+1$ range. Statistical analysis of the results revealed no major discrepancies. In the case of kanamycin, six minor errors were noticed, in case of cephalexine four and in case of penicillin two. The percentage of minor errors was, in all cases, below the acceptable discrepancy rate.

The aim of this study was also to establish differences in the sensitivity patterns of bovine and ovine $S$. aureus isolates to various antimicrobials. A comparison of the E-test results of bovine $(\mathrm{n}=76)$ and ovine $(\mathrm{n}=16) S$. aureus strains, which were used in our investigation,

Table 5. Discrepancy rates for ampicillin.

\begin{tabular}{lllll}
\hline MIC Range & Number & Very major & Major & Minor \\
\hline$\geq \mathrm{R}+1$ & 26 & $1(3.8)$ & $\mathrm{NA}$ & 0 \\
$\mathrm{R}+\mathrm{S}$ & 10 & 0 & 0 & 0 \\
$\leq \mathrm{S}-1$ & 56 & NA & 0 & 0 \\
Total & 92 & $1(1.1)$ & 0 & 0 \\
\hline
\end{tabular}




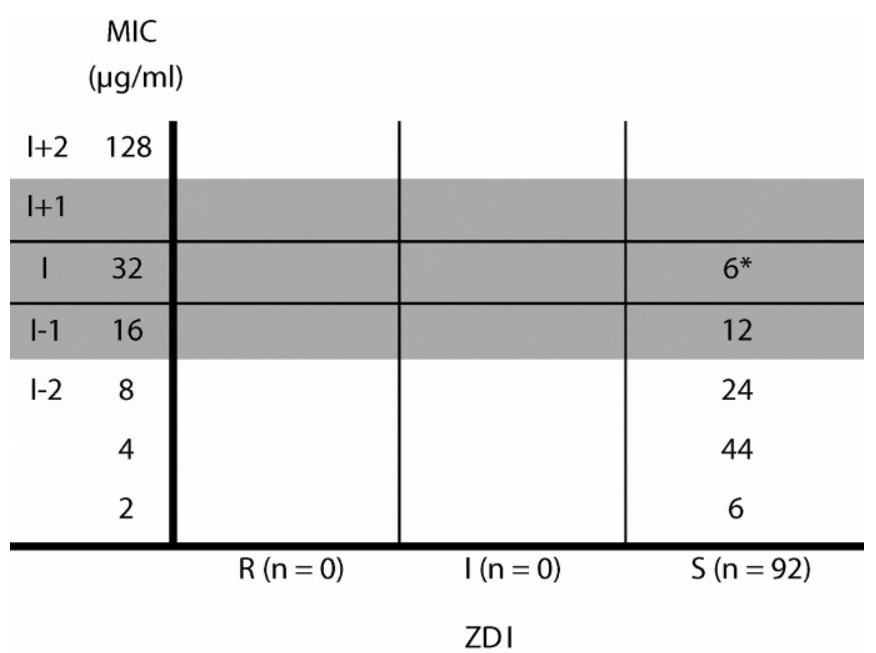

Figure 4. Comparison of the diameter of the zone of inhibition and the minimal inhibitory concentration of 92 Staphylococcus aureus strains for kanamycin. Distribution of the strains between interpretation zones S, I, and R for the disk diffusion and the E-test (MIC). $\mathrm{ZDI}=$ Zone diameter interpretation; $\mathrm{MIC}=$ minimal inhibitory concentration; $\mathrm{S}=$ sensitive $\geq 18 \mathrm{~mm} ; \mathrm{S}=$ sensitive $\leq 16(\mu \mathrm{g} / \mathrm{ml}) ; \mathrm{I}=$ intermediate 14 to $17 \mathrm{~mm}$; I = intermediate $32(\mu \mathrm{g} / \mathrm{ml}) ; \mathrm{R}=$ resistant $\leq 13 \mathrm{~mm} ; \mathrm{R}=$ resistant $\geq 64(\mu \mathrm{g} / \mathrm{ml})$; $*$ minor error.

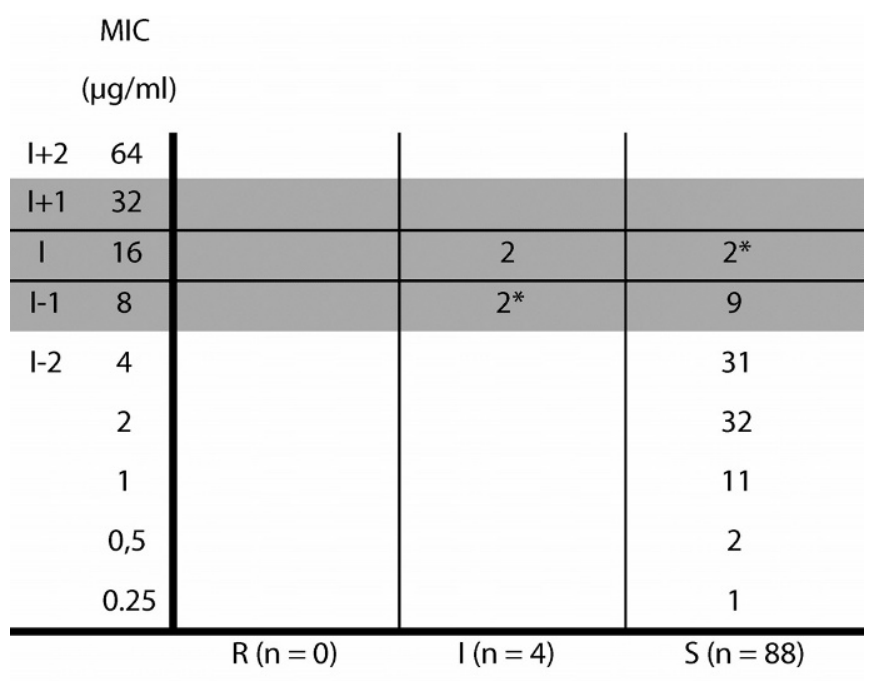

ZDI

Figure 5. Comparison of the diameter of the zone of inhibition and the minimal inhibitory concentration of 92 Staphylococcus aureus strains for cephalexine. Distribution of the strains between interpretation zones S, I, and R for the disk diffusion and the E-test (MIC). $\mathrm{ZDI}=$ Zone diameter interpretation; $\mathrm{MIC}=$ minimal inhibitory concentration; $\mathrm{S}=$ sensitive $\geq 18 \mathrm{~mm} ; \mathrm{S}=$ sensitive $\leq 8(\mu \mathrm{g} / \mathrm{ml}) . \mathrm{I}=$ intermediate $14-17 \mathrm{~mm}$; I = intermediate $16(\mu \mathrm{g} / \mathrm{ml}) ; \mathrm{R}=$ resistant $\leq 14 \mathrm{~mm} ; \mathrm{R}=$ resistant $\geq 32(\mu \mathrm{g} / \mathrm{ml}) ;{ }^{*}=$ minor error.
Table 6. Summary of agar diffusion test and E-Test data of Staphylococcus aureus strains that were isolated from bovine $(\mathrm{n}=76)$ and ovine $(\mathrm{n}=16)$ IMI. $^{1}$

\begin{tabular}{lcclllll}
\hline & \multicolumn{3}{c}{ Cows } & & \multicolumn{3}{c}{ Sheep } \\
\cline { 2 - 4 } \cline { 6 - 8 } & $\mathrm{S}$ & $\mathrm{I}$ & $\mathrm{R}$ & & $\mathrm{S}$ & $\mathrm{I}$ & $\mathrm{R}$ \\
Antibiotic & $(\%)$ & $(\%)$ & $(\%)$ & & $(\%)$ & $(\%)$ & $(\%)$ \\
\hline Penicillin & 59.2 & 2.6 & 38.2 & 93.7 & & 6.3 \\
Ampicillin & 61.8 & & 38.2 & & 93.7 & & 6.3 \\
Oxacillin & 100 & & & & 100 & & \\
Kanamycin & 92.1 & 7.9 & & & 100 & & \\
Cephalexine & 96.1 & 3.9 & & & 93.7 & 6.3 & \\
\hline
\end{tabular}

${ }^{1} \mathrm{~S}=$ sensitive; $\mathrm{I}$ = intermediate; $\mathrm{R}=$ resistant.

reveals a lower resistance rate among ovine isolates for penicillin and ampicillin (Table 6). This can be explained with a smaller incidence of antibiotic treatment in this animal species and probably also with appearance of different $S$. aureus genotypes in the ovine mammary gland.

After analyzing the data obtained in this study the question "Why does antibiotic mastitis therapy fail?" still remains unanswered. Antibiotic resistance or resistance development of mastitis pathogens is obviously not the key to explain this problem. The explanation for the failure should therefore be searched between other factors, which also influence the outcome of the therapy.

\section{CONCLUSIONS}

In accordance with the results of this study, the following conclusions can be made:

In comparison with previous studies no major differences in sensitivity of $S$. aureus to antimicrobials was detected; ovine $S$. aureus strains expressed a higher sensitivity rate than bovine strains; the overall results of the agar disk diffusion test and the E-test were in satisfactory agreement.

\section{REFERENCES}

Beveridge, W. I. B. 1983. Mastitis in ewes. Anim. Health Aust. 4:148-149.

Brunden, M. N., G. E. Zurenko, and B. Kapik. 1992. Modification of the error-rate bounded classification scheme for use with two MIC break points. Diagn. Microbiol. Infect. Dis. 15:135-140.

Craven, N., J. C. Anderson, and T. O. Jones. 1986. Antimicrobial drug susceptibility of Staphylococcus aureus isolated from bovine mastitis. Vet. Rec. 118:290-291.

Easmon, C. S. F., and C. Adlam. 1983. Staphylococci and Staphylococcal Diseases. Academic Press, London, UK.

Harmon, R. J., R. J. Eberhart, D. E. Jasper, B. E. Langlois, and R. A. Wilson. 1990. Microbiological Procedures for the Diagnosis of Bovine Udder Infection. Natl. Mastitis Counc., Inc., Arlington, VA.

Jasper, D. E., and N. C. Jain. 1966. Hemolytic behaviour of staphylococci isolated from cows milk. Can. J. Comp. Vet. Med. Sci. 30:63-70. 
Jasper, D. E., F. Infante, and J. D. Dellinger. 1985. Efficacy of the API Staph-Ident system for identification of staphylococcus species from milk. Am. J. Vet. Res. 46:1263-1267.

Kloos, W. E., and P. B. Smith. 1980. Aerobic bacteria. Page 83 in Manual of Clinical Microbiology, 3rd ed. E. H. Lenette, A. Balows, J. Hausler, and J. P. Truant, eds. Washington, DC.

Kloos, W. E., and J. F. Wolfshohl. 1982. Identification of Staphylococcus species with the API Staph-Ident system. J. Clin. Microbiol. 16:509-516.

Lam, T. J. G. M., A. Pengov, Y. H. Schukken, J. A. H. Smit, and A. Brand. 1995. The differentiation of Staphylococcus aureus from other Micrococcaceae isolated from bovine mammary glands. Appl. Microbiol. 79:69-72.

Lipman, L. J. A., A. de Nijs, T. J. G. M. Lam, J. A. Rost, L. van Dijk, Y. H. Schukken, and W. Gastra. 1996. Genotyping by PCR, of Staphylococcus aureus strains, isolated from mammary glands of cows. Vet. Microbiol. 48:51-55.

Matthews, K. R., S. J. Kumar, S. A. O'Conner, R. J. Harmon, J. W. Pankey, L. K. Fox, and S. P. Oliver. 1994. Genomic fingerprints of Staphylococcus aureus of bovine origin by polymerase chain reaction-based DNA fingerprinting. Epidemiol. Infect. 112:177186.

McDonald, J. S., and A. J. Anderson. 1981. Antibiotic sensitivity of Staphylococcus aureus and coagulase negative staphylococci isolated from infected bovine mammary glands. Cornell Vet. 71:391-396
Metzler, C. M., and R. M. DeHaan. 1974. Susceptibility tests of anaerobic bacteria: Statistical and clinical considerations. J. Infect. Dis. 130:588-594.

Owens, W. E., C. H. Ray, J. L. Watts, and R. J. Yancey. 1997. Comparison of success of antibiotic therapy during lactation and results of antimicrobial susceptibility tests for bovine mastitis. J. Dairy Sci. 80:313-317.

Pengov, A. 2001. The role of coagulase-negative Staphylococcus spp. and associated somatic cell counts in the ovine mammary gland. J. Dairy Sci. 84:572-574.

Pengov, A., S. Ceru, and A. Jurčevič. 2001. Treatment of bovine udder infections caused by Staphylococcus aureus. Slov. Vet. Res. 38:151-159.

Phuektes, P., P. D. Mansell, and G. F. Browning. 2001. Multiplex polymerase chain reaction assay for simultaneous detection of Staphylococcus aureus and streptococcal causes of bovine mastitis. J. Dairy Sci. 84:1140-1148.

Thornsberry, C., and L. K. McDougal. 1983. Successful use of broth microdilution in susceptibility tests for methicillin-resistant (heteroresistant) staphylococci. J. Clin. Microbiol. 18:1084-1091.

Watts, J. L., and R. J. Yancey. 1994. Identification of veterinary pathogens by use of commercial identification systems and new trends in antimicrobial susceptibility testing of veterinary pathogens. Clin. Microbiol. Rev. 7:346.

Wilson, C. D. 1973. Use of antibiotics against mastitis. Vet. Rec 92:515. 